\title{
Novos Autos da Revolução para sete "criaturas inteiras" de António Lobo Antunes
}

\author{
Christine Zurbach
}

Autos da Revolução,
a partir de textos de
António Lobo Antunes,
enc. Pierre-Étienne
Heymann, CENDREV/
TA, 2014 (cenografia), fot. Paulo Nuno Silva.

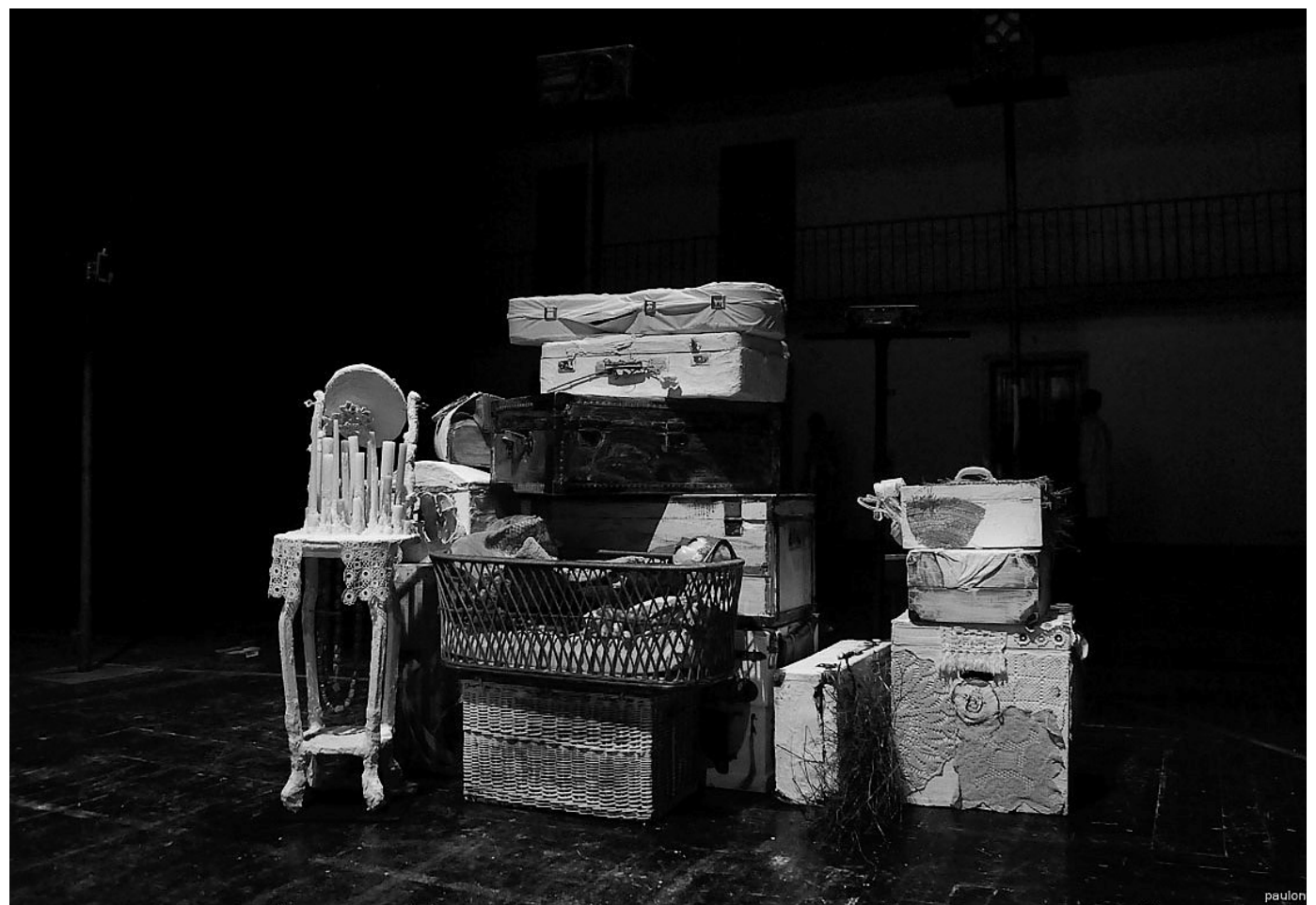

Título: Autos da Revolução. Textos: António Lobo Antunes (trechos de Conhecimento do inferno, 1980; Fado alexandrino, 1983; Auto dos sanados, 1985; O manual dos Inquisidores, 1996; Exortação aos crocodilos, 1999). Montagem e encenação: Pierre-Étienne Heymann com a colaboração de Rosário Gonzaga. Direcção musical e sonoplastia: Gil Nave. Cenário e figurinos: Elsa Blin. Iluminação: António Rebocho, assistido por Sergio Santafé (estagiário do Institut del Teatre de Barcelona). Interpretação: Mário Spencer, Rosário Gonzaga, Maria Marrafa, Bruno Martins, Tânia da Silva e Jorge Baião. Voz. Rui Nuno. Co-produção: Centro Dramático de Évora (CENDREV) / Companhia de Teatro do Algarve (ACTA). Local e data de estreia: Teatro Garcia de Resende, Évora, 27 de Março de 2014.

Para o frequentador mais assíduo do Centro Dramático de Évora (CENDREV), a última criação da companhia, estreada no Dia mundial do Teatro no palco do Teatro Garcia de Resende em co-produção com a Companhia de Teatro do Algarve (ACTA), apresenta, numa primeira percepção, uma forte similitude com o espectáculo igualmente intitulado Autos da Revolução, concebido na ocasião do trigésimo aniversário da Revolução do 25 de Abril: como em 2004, o encenador convidado é o francês Pierre-Étienne Heymann, que assina a sua sexta encenação para a companhia eborense, e o autor dos textos é, de novo, o escritor Lobo Antunes, ambos convocados para o mesmo acto comemorativo, dez anos depois.
Mas estes Autos não são uma mera reprise da primeira versão e também não visam apenas criar algo que seja original ou novo. Neste caso, a inovação patente na obra que nos é proposta em 2014 é de outra ordem, e assenta fundamentalmente numa intensificação dos meios postos ao serviço da reflexão crítica a produzir pelo espectador. Nos novos Autos, Heymann parte da importância objectiva da passagem do tempo sobre os dias de Abril de 1974 que deram corpo à mudança da história de/em Portugal. São muito visiveis as marcas sobre os seres e as coisas que sustentam a fábula, ambos envelhecidos, de aparência poeirenta ou decadente. Todo o ambiente luminoso e plástico do espectáculo serve para sublinhar uma patine 


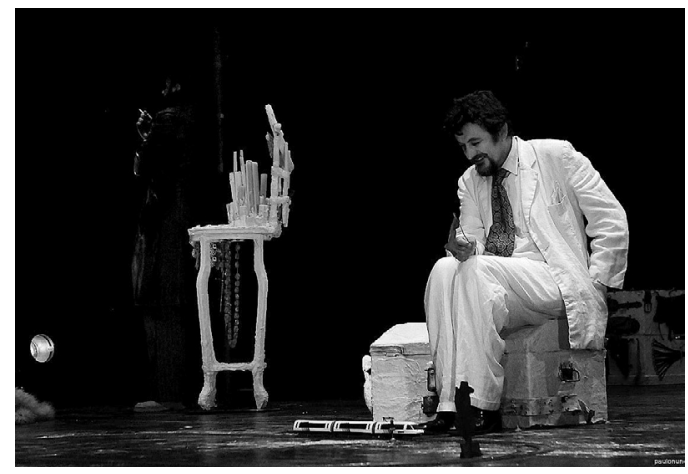

difusa, com um recurso dominante a tonalidades cinzentas ou esbatidas, jogando com a cor preta ou o branco das roupas, e também da maquilhagem dos rostos das personagens. São apenas contrariadas pelo vermelho dos cravos atirados perto do fim para o fosso de orquestra e pelo vermelho no peito dos corvos da quinta, abatidos a tiro, que sairão de uma mala aberta pela filha do caseiro que, num gesto mecânico de trabalho, agora carregado de um novo significado, os vai lavar do sangue que os mancha.

Com uma dramaturgia nascida, em termos conceptuais e teatrais, da distância - temporal, mas também discursiva - que se vai acentuando em relação ao evento histórico que voltou a ser o fio condutor do espectáculo, a própria evocação da Revolução dos Cravos tornava

necessariamente mais premente a atenção que devia ser dada às interrogações que levanta tal comemoração hoje. Assim os Autos recusam o tom laudatório que seria expectável (ou porventura desejável para alguns), e questionam sobretudo o tempo presente, o da recepção da narrativa-espectáculo por um espectador que vive diariamente no contexto deceptivo e disfórico de um pais de costas voltadas para promessas que ainda eram vivas em 2004, mas que vão perdendo a sua aura. É disso sobretudo que estes Autos nos querem falar. E por isso não terão por vocação consolar-nos. Pelo contrário, dele saimos desassossegados e inquietos. ${ }^{1}$ Como na primeira versão, a fábula narrada tem inicio na madrugada do dia em que se deu o acontecimento histórico, a queda do regime, e termina à noite, com o triunfo do Movimento das Forças Armadas, confirmado pela voz de um locutor da rádio. Nesta versão, cabe ao carregador Abílio, sobrinho e empregado do dono de uma empresa de mudanças,

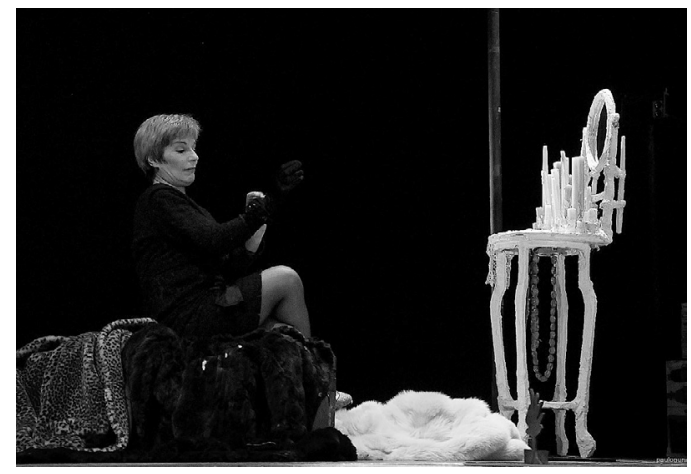

Autos da Revolução, a partir de textos de António Lobo Antunes, enc. Pierre-Étienne Heymann, CENDREV / ACTA, 2014 (< Jorge Baião; $>$ Rosário Gonzaga), fot. Paulo Nuno Silva.

guiar o espectador no labirinto dos fragmentos da obra de Lobo Antunes, reunidos numa montagem que alinha os momentos recordados pelas personagens, com as emoções que as assaltaram, retratadas num jogo teatral contido e rigoroso, cuja intensidade é cuidadosamente medida pelos intérpretes. Alguns, actores do Cendrev são já mestres nesse exercicio de sensibilidade pedido por Heymann, pelo que Rosário Gonzaga, Maria Marrafa e Jorge Baião fazem justiça à particularidade da escrita do romancista. A esses juntaram-se três actores da companhia ACTA, com a prestação segura de Mário Spencer, a boa interpretação da complexidade do perfil do militante por Bruno Martins, e a proposta sensivel de Tânia da Silva, ancorada num difícil trabalho vocal e rítmico, criado a partir da escuta da partitura das suas falas.

0 percurso de Abílio cruza-se com o das restantes personagens, algumas já utilizadas em 2004. São figuras sem nome, designadas pela sua função, como o militante, a burguesa, o banqueiro, a filha do caseiro, ao lado de outras, humanizadas, como Abílio, Mimi, a jovem mulher surda, casada com um contra-revolucionário membro do ELP, e Titina, a velha e dedicada governanta da quinta. A personagem do dono da quinta que pontuava os primeiros Autos como figura emblemática do mundo do "antigamente", deixou de ter uma presença física, e já só aparece nas falas da filha do caseiro, que evoca obsessivamente, assombrada e aterrorizada por ele, a violência sexual que exerce sobre ela. Heymann manteve o núcleo forte das figuras mais familiares para os leitores das primeiras ficções de Lobo Antunes em torno dessa época da História de Portugal - retratadas num tom ao mesmo tempo irónico, amargo e desapaixonado. Essa amostra quase caricatural da velha burguesia rural
Ler a esse respeito o texto "Há dez anos", em "perguntas inevitáveis com o andar do tempo e à luz da fervura que sacode o pais actualmente" (Folha de sala do espectáculo, Autos da Revolução, Évora Cendrev \& ACTA, Março 2014). que Heymann fala de 


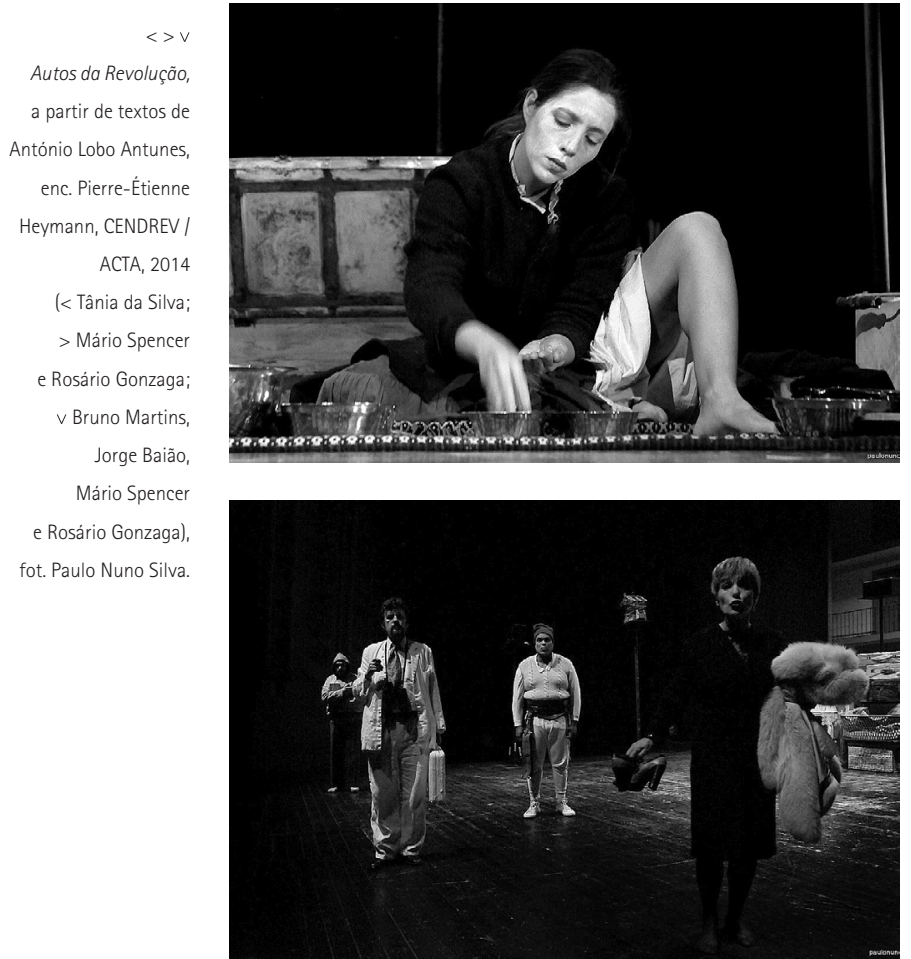

salazarista - que o 25 de Abril assustou - a agitar-se diante dos olhos da personagem do escritor, cuja presença silenciosa produz uma mise en abîme da fábula contada é a matéria do espectáculo.

0 guião divide as falas cruzadas, sempre monologadas, das personagens que constituem o suporte verbal e textual do espectáculo em nove quadros, organizados sucessivamente a partir de cada personagem, cujo nome é dito em voz off, no escuro, anunciando o retrato animado de cada uma delas. 0 procedimento põe em primeiro plano a opção de privilegiar uma percepção da História não tanto pelos acontecimentos em si, mas pelo percurso interior das personagens. A moldura do conjunto é formada pelo prólogo e pelo epílogo lidos pelo escritor já referido aqui, sentado na direita baixa do proscénio. É uma personagem criada para ser interpretada por um espectador, diferente em cada espectáculo, o que remete hipoteticamente para a plateia os conteúdos dos dois textos que serão lidos por ele. Retirados de Auto dos danados e de Conhecimento do inferno, eram atribuídos na versão de 2004 à exilada Ana, o primeiro, que evocava com despeito e também alguma melancolia a pequenez de Portugal visto do Brasil, e o segundo, a um médico psiquiatra, duplo do escritor Lobo Antunes que, num texto sarcástico, ironizava sobre a conversão generalizada dos portugueses à democracia ou até ao socialismo.

A presença desse mesmo médico confunde-se com a do escritor. Também interlocutor mudo das personagens em cena que o interpelam pontualmente para Ihe confiarem as suas narrativas, induz uma ligação que articula as duas versões, numa hipotética passagem das personagens da versão de 2004 para uma nova etapa na sua história, talvez entradas numa demência que se adivinhava. É sugerida no início do espectáculo, em que a entrada em cena de cada actor-personagem é feita pela abertura por um técnico-enfermeiro da porta do seu camarim-quarto de hospital, à vista do público, no fundo do palco

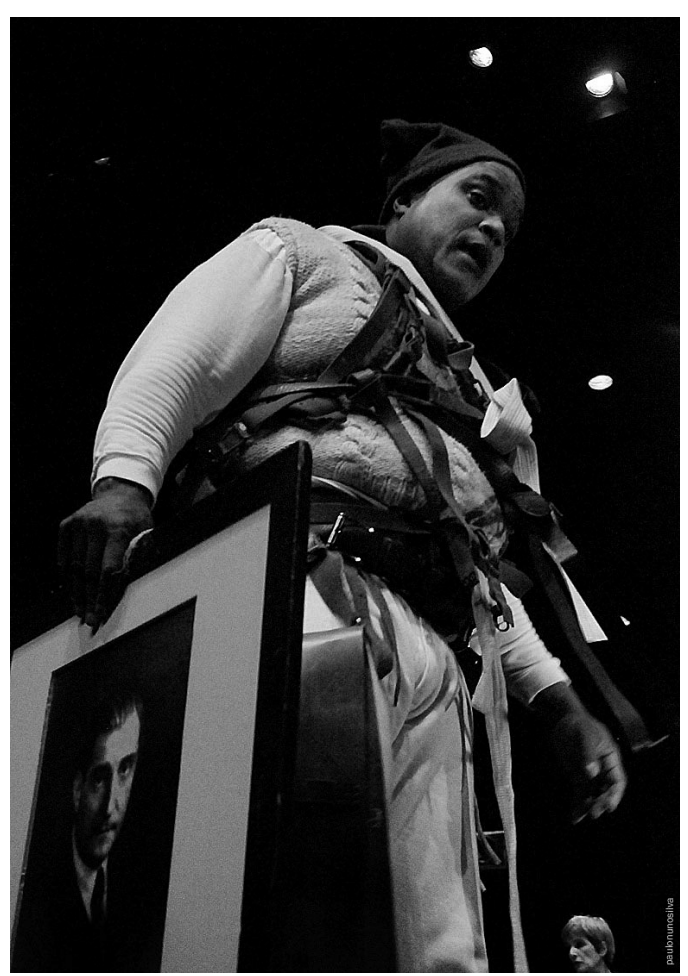

totalmente aberto, sem cenário. Esse apontamento é retomado em todas as circulações das personagens no palco, confinadas às paredes invisiveis de uma sala de dia num hospital, delimitada pela dezena de objectos, malas e malotes, que vão ser deslocados e transportados pelo carregador Abílio ao longo das cenas em função da sucessão dos quadros. Esse espaço é o do fechamento, onde se circula sem fim, ou se estaca, paralisado, mas ele contém também a possibilidade de cada personagem encontrar um canto que seja seu, um refúgio para onde cada um pode regressar. No fim, todos irão dirigir-se ao escritor, despedindo-se ao fim do seu dia e do (seu) espectáculo. As suas vozes pela primeira vez vão confundirse, sobrepondo-se, antes de se apagarem, no escuro.

Para a cenografia, a escultora Elsa Blin propõe um belissimo tratamento do espaço onde se desenvolve o jogo dos actores. É uma proposta plástica que se serve da linguagem da escultura para definir e construir os lugares da representação, materializados pela colocação dos objectos em pontos disseminados no palco que correspondem ao universo de cada um: por exemplo, uma mala maior, entre outras de diversas dimensões, abriga o militante, e também livros, roupas, máscaras e retratos de Marx ou Salazar que este vai exibindo, e permite significar a complexidade da relação desta personagem com um espaço prisional ambíguo, ao mesmo tempo repressivo e protector contra um mundo exterior que acabará - ao dar-Ihe a liberdade abrindo os portões de Caxias - por confrontá-lo com a sua própria inépcia. Um toucador, enfeitado com rendas coladas ou tecidos envelhecidos, também será um altar, ao lado de uma colcha de tear, perímetro de trabalho da filha do caseiro, que repete à exaustão os gestos de lavar ou esfregar bacias, ou o seu próprio corpo violentado e sujo. Mastros plantados em fila, de cada lado do território de jogo assim criado, suportam postos de rádio, bem como uma gaiola com um pássaro, em contraponto visual e sonoro. Os 
objectos de cada personagem falam-nos do seu mundo restrito, ao mesmo tempo simbólico e obsessivo, como casacos de pele, um berço de boneca, uma longa trança, uma pista do comboio eléctrico de brincar, tachos, panelas e baldes, uma maleta completada por binóculos, charutos e telefone... São parte integrante das narrativas de cada um. Com eles a fábula desenvolve-se em imagens intensas, como no sétimo quadro, intitulado "Coro", em que se lançam cravos para o fosso da orquestra ou se desvendam os cadáveres dos corvos.

A partitura sonora do espectáculo revela as vozes das personagens nos seus monólogos de encontro à musicalidade e ritmo das falas escritas por Lobo Antunes, e de que os actores se apropriaram numa fase inicial do trabalho com o encenador. Nesta montagem, os ruídos que envolvem os acontecimentos, nomeadamente os ruidos da quinta, são uma presença constante, como é o ladrar dos cães, o grito dos corvos, o ranger dos baldes de metal, bem como o som da rádio, esse objecto emblemático do dia 25 de Abril que aparece no palco na forma de seis aparelhos antigos, postos no alto de estacas e iluminados nas mudanças de cena. 0 som de um pequeno transistor de bolso do militante, o das marchas militares como o hino do MFA - leitmotiv do espectáculo - ou das canções revolucionárias, da ópera, do fado de Coimbra ou de Lisboa, compõem a selecção de apontamentos musicais que conotam personagens ou lugares. Uma guitarra acompanha Abílio quando canta o Fado da prostituta da Rua da de Santo António da Glória, de Lobo Antunes, e o militante canta para Mimi El dia que me quieras de Carlos Gardel...

Nesta proposta, o encenador dá ao contributo dos actores uma visibilidade de primeiro plano. Encerradas num percurso em cena - quase autista, maníaco e repetitivo -, traduzido em trajectórias individuais, as personagens, que interpretam, remoem os acontecimentos que transformaram as suas vidas. A sua memória surge desfiada, ora com prazer, ora com dor, como no jogo de Mimi, que povoa o seu mundo de mulher-criança, infantilizada, com um berço, uma boneca-homem em ponto pequeno, perucas e frascos de verniz, cantarolando em voz baixa, ou como nas recordações da burguesa Sofia que acaba por se confundir quase com os seus casacos de peles, que veste e despe, em tentativas repetidas para os salvar, e que, histericamente, sucumbirá a um ataque de loucura e será rapidamente levada de cena, numa cama-maca, pelo enfermeiro. Ao revelar uma maior liberdade pessoal, no plano político e ideológico quanto à visão que propõe do que chama, na folha de sala do espectáculo, a "lenda dourada do 25 de Abril", a visão de Heymann é filtrada, menos pelo discurso de compaixão assumido pelo romancista em relação às suas criaturas romanescas, do que por um olhar exterior, que distancia o que nos é mostrado, num estilo que também pode ser tocante quando se trata de personagens indefesas, como a filha do caseiro ou Mimi.

Neste quadro comemorativo, o encenador oferecenos um espectáculo sombrio, conotado pela tristeza da cor da época que atravessamos. É assim que o encenador, apesar de ter voltado a convidar, para a festa dos 40 anos da Revolução dos Cravos, sete "criaturas inteiras" do romancista Lobo Antunes, a verdade é que Ihes retirou a tonalidade melancólica - que é uma marca de um escritor, também cronista do quotidiano de um pais sem heróis -, tornando disfórico e até deceptivo o se discurso. E, apesar dos cravos vermelhos, que renascem fugazmente no palco simbolizando a festa, a verdade é que eles se vão acumulando no fosso da orquestra, depois de lançados em gestos lentos, sob o olhar impassivel do escritor, que permaneceu silencioso durante toda a representação, como quem observa clinicamente, sem emoção, o espectáculo que se vai desenrolar até ao cair do pano.

Mas o espectador é surpreendido ainda por uma última imagem: um caminho de luz, traçado e recortado no chão desde o fundo do palco, que vai conduzir Titina, a velha governanta do doutor, até às luzes da ribalta onde fará a última narrativa do espectáculo, a da sua expulsão brutal da quinta pelo patrão, juntamente com os "comunistas", e da constatação que a mala que contém todos os seus haveres "não pesava quase nada". Termina calçando, em silêncio, o sapato que tinha vindo buscar, num gesto contido e comovente de Rosário Gonzaga que, delicadamente, nos oferece, nos últimos minutos do espectáculo, com esse retrato doloroso da alienação devota confrontada com a verdade crua da servidão, um sinal de justa indignação. 